\title{
Laboratory Investigations of Enhanced Sulfate Reduction as a Groundwater Arsenic Remediation Strategy
}

\author{
A. R. KEIMOWITZ ${ }^{\star} \dagger, \ddagger$, B. J. MAILLOUX§, P. COLE $\$$, M. STUTE $\ddagger, \S$, H. J. SIMPSON ${ }^{\dagger} \ddagger$, and S. \\ N. CHILLRUD ${ }^{\ddagger}$ \\ Department of Earth and Environmental Sciences, Columbia University, New York, New York \\ 10027, Lamont-Doherty Earth Observatory of Columbia University, Palisades, New York 10964, \\ and Department of Environmental Sciences, Barnard College, New York, New York 10027
}

\begin{abstract}
Landfills have the potential to mobilize arsenic via induction of reducing conditions in groundwater and subsequent desorption from or dissolution of arsenic-bearing iron phases. Laboratory incubation experiments were conducted with materials from a landfill where such processes are occurring. These experiments explored the potential for induced sulfate reduction to immobilize dissolved arsenic in situ. The native microbial community at this site reduced sulfate in the presence of added acetate. Acetate respiration and sulfate reduction were observed concurrent with dissolved iron concentrations initially increasing from $0.6 \mu \mathrm{M}\left(0.03 \mathrm{mg} \mathrm{L}^{-1}\right)$ to a maximum of $111 \mu \mathrm{M}\left(6.1 \mathrm{mg} \mathrm{L}^{-1}\right)$ and subsequently decreasing to $0.74 \mu \mathrm{M}\left(0.04 \mathrm{mg} \mathrm{L}^{-1}\right)$. Dissolved arsenic concentrations initially covaried with iron but subsequently increased again as sulfide accumulated, consistent with the formation of soluble thioarsenite complexes. Dissolved arsenic concentrations subsequently decreased again from a maximum of $2 \mu \mathrm{M}\left(148 \mu \mathrm{g} \mathrm{L}^{-1}\right)$ to $0.3 \mu \mathrm{M}\left(22 \mu \mathrm{g} \mathrm{L}^{-1}\right)$, consistent with formation of sulfide mineral phases or increased arsenic sorption at higher $\mathrm{pH}$ values. Disequilibrium processes may also explain this second arsenic peak. The maximum iron and arsenic concentrations observed in the lab represent conditions most equivalent to the in situ conditions. These findings indicate that enhanced sulfate reduction merits further study as a potential in situ groundwater arsenic remediation strategy at landfills and other sites with elevated arsenic in reducing groundwater.
\end{abstract}

\section{Introduction}

Arsenic (As) is commonly found at elevated levels in contaminated sites and is the second most common contaminant of concern at National Priority List (NPL)/Superfund sites (1). Approximately $35 \%$ of the 718 Superfund sites where As is of concern are landfills (2). Arsenic could have been improperly disposed at a subset of these sites; however, it has been shown that landfill leachates can mobilize naturally occurring As from aquifer materials and thereby generate substantially elevated levels of As in the groundwater beneath the landfills (3-5). Given the apparent widespread occurrence of this problem, efficient remediation techniques for high As groundwater could be very helpful.

\section{() 2007 American Chemical Society}

*Corresponding author phone: (845)365-8603; fax: (845)365-8155; ark@1deo.columbia.edu.

tDepartment of Earth \& Environmental Sciences, Columbia University.

\$Lamont-Doherty Earth Observatory of Columbia University.

$\S_{\text {Barnard College. }}$

Supporting Information Available

Geochemical parameters from groundwater monitoring, reactions for formation of aqueous As-S species, and mass balances for microcosm and reactor incubation experiments. This material is available free of charge via the Internet at http://pubs.acs.org. 
Groundwater extraction and treatment is the most widespread intervention for groundwater with elevated arsenic (1). Although removal of dissolved As from extracted groundwater in the treatment systems is usually effective, these systems generally cannot accomplish major in situ decreases of groundwater [As] on reasonable time scales (6). Therefore, alternate intervention strategies, such as in situ remediation, are of potential value. In situ remediation generally attempts to exploit a decreased As mobility under altered subsurface environments, such as more oxic conditions in which [As] decreases (7) in part due to sorption onto Fe (hydr)oxides $(8,9)$; sorption onto zerovalent iron $(10,11)$; or more reducing, sulfidic conditions in which the As mobility is relatively low due to sorption or coprecipitation with Fe sulfide minerals (12-14) and/or formation of As sulfides (15-17). Therefore, it may be feasible in a number of circumstances to decrease groundwater [As] in situ by enhancement of sulfate reduction and formation of sulfide minerals that are generally quite stable in suboxic groundwater (18).

At the Nickel Rim mine site in Ontario, an electron donor was buried in the subsurface and stimulated sulfate reduction that promoted the removal of iron and sulfate from solution. However, the effects of this intervention on dissolved arsenic were not investigated (19). Previous laboratory microcosm incubations (20) and column experiments (21-23) have demonstrated that sulfate-reducing bacteria can immobilize As. These field and laboratory experiments were focused on acid mine drainage sites with $\mathrm{pH}$ values of 4.5-6. Such highly acidic sites have significantly different geochemical conditions from those at non-mining As contaminated sites (e.g., refs 3 and 5).

Arsenic-sulfide interactions are strongly pH-dependent and relatively complex (24-26). Arsenic immobilization by sulfate reduction may occur via different pathways under circumneutral $\mathrm{pH}$ conditions than under acidic conditions (27), as the reactions that control As solubility in the presence of sulfide are $\mathrm{pH}$-dependent (26). Arsenic solubility has been shown to decrease, then increase, then decrease again with progressively increasing sulfide concentrations; the maximum As solubility occurs at about $0.1 \mathrm{mM}$ sulfide, depending on the $\mathrm{pH}$ (26). Iron concentrations have also been shown to affect arsenic-sulfide behavior $(16,28)$. Our research was intended to explore the feasibility of enhanced sulfate reduction as an As remediation strategy under neutral to mildly alkaline $\mathrm{pH}$ conditions at a landfill site in Winthrop, ME. At this site, groundwater is reducing (ORP $\approx-10$ to $-160 \mathrm{mV}$, median value $-90 \mathrm{mV}$ ) and contains abundant sulfate (mean concentration $\sim 3 \mathrm{mM}$ ) due to reinjection of extracted groundwater treated with sulfuric acid and subsequently neutralized, but available evidence also indicates that the extent of sulfate reduction may be relatively limited in time and space (3). Our results indicate that in situ precipitation of sulfide mineral phases may be a viable remediation strategy at some As contaminated landfill sites.

\section{Study Site}

The sediment used in this study was from the Winthrop Landfill in southeastern Maine, which is currently on the NPL and has been the focus of a number of previous studies $(3,7$, 29). The site was initially excavated as a sand and gravel pit in the 1920s, and then, primarily, municipal wastes were dumped into this unlined pit from the 1930s to the 1970s; the landfill was subsequently covered with an impermeable clay cap, and a groundwater extraction and treatment system was constructed to lower the concentrations of volatile organic compounds in local groundwater (30). This landfill is located in an unconsolidated glacial till and outwash with arsenic concentrations of $\sim 5 \mathrm{mg} \mathrm{kg}^{-1}$ (dry weight), in the range of typical crustal abundances of $3-10 \mathrm{mg} \mathrm{kg}^{-1}(31,32)$. The dissolved As in groundwater does not originate in significant amounts from waste in the landfill but rather is mobilized from the natural aquifer sediments as a result of decomposition of organic matter originating within the landfill that lowers the $E_{\mathrm{h}}$ and enables the mobilization of $\mathrm{Fe}$ and As from the sediments $(3,29)$. Groundwater As concentrations at this site as high as $10.7 \mu \mathrm{M}(800 \mu \mathrm{g}$ 
$\left.\mathrm{L}^{-1}\right)$ have been observed, and persistent plumes of $\sim 4 \mu \mathrm{M}\left(\sim 300 \mu \mathrm{g} \mathrm{L}^{-1}\right)$ have been found extending hundreds of meters in several directions away from the perimeter of the landfill.

\section{Materials and Methods}

Sediments collected during the installation of four monitoring wells in the central region of the landfill were composited. Characteristics of this sediment have been described in detail elsewhere (3); the poorly sorted (mostly grayish) sediments were primarily sand and gravel. Artificial groundwater was synthesized to replicate the inorganic composition of groundwater samples without arsenic, iron, or manganese (Supporting Information Table 1). Aqueous field samples discussed here were collected in January to May 2000 and analyzed for dissolved species including Fe and As using EPA method 6010. Details have been reported elsewhere (3). Unless otherwise specified, all reagents employed were ACS reagent grade. Sterile techniques were followed; all materials that were used in the incubations except sediments were sterilized by autoclave.

Two types of experiments were conducted in which sediment, water, and added acetate were incubated together: (i) a reactor incubation conducted in a large vessel $(\sim 9 \mathrm{~L})$ with integrated electrodes from which small aqueous phase samples were periodically removed and analyzed and (ii) microcosm incubations in $\sim 60 \mathrm{~mL}$ bottles from which both aqueous phase and sediment samples were removed and analyzed. Both experiments were conducted on a table-shaker, in the dark at room temperature and were not stirred. The experiments were designed to be analogous and complementary, although not identical.

\section{Analytical Instrumentation}

All water samples withdrawn were filtered through a $0.2 \mu \mathrm{m}$ sterile cellulose acetate membrane syringe filter purged with $\mathrm{N}_{2}$. Ion chromatography (IC) samples were filtered, frozen, and subsequently analyzed for acetate, $\mathrm{F}^{-}, \mathrm{Cl}^{-}, \mathrm{Br}^{-}, \mathrm{NO}_{2}^{-}, \mathrm{NO}_{3}^{-}, \mathrm{PO}_{4}^{-}$, and $\mathrm{SO}_{4}{ }^{-}$ on a Dionex DX-100 (Sunnyvale, CA) run in anion self-regenerating suppression mode with a carbonate buffer eluent, an AG-14 guard column, and a $4 \mathrm{~mm} \times 250 \mathrm{~mm}$ AS-14A analytical column. Separation of acetate and fluoride was routinely achieved, but resolution of acetate from other volatile organic acids (e.g., formate, propionate, etc.) was not investigated, and interferences were possible. Inductively coupled plasma mass spectrometry (ICP-MS) samples were acidified to $1 \%$ with Optima grade nitric acid and analyzed on a high-resolution Axiom single collector instrument (Thermo Elemental, Bremen, Germany) as described previously (33). Sulfide (method 4500D) and alkalinity (method 2320) were immediately analyzed after collection using standard methods (34). Fe oxidation states were determined by the ferrozine method (35).

\section{Reactor Experiment}

The reactor was custom built and consisted of a $\sim 9 \mathrm{~L}$ reservoir with a gasket-sealed cap, two syringe sample ports, and a movable piston to allow removal of fluid samples without the introduction of headspace gases. A Horiba U-22 multi-parameter sensor continuously logged dissolved oxygen, oxidation-reduction potential (ORP), $\mathrm{pH}$, electrical conductivity, and temperature. The $\mathrm{DO}, \mathrm{pH}$, and conductivity sensors of this meter were calibrated before and after incubation, and the ORP sensor was checked before and after incubation with the manufacturer's "check" solutions of +98 and $+258 \mathrm{mV}$. Drift was $<20 \mathrm{mV}$ ORP over the course of the experiment. The reactor was filled with $\sim 3 \mathrm{~kg}$ of wet sediment and $\sim 8.5 \mathrm{~L}$ of artificial groundwater $(20 \mathrm{mM})$ in added acetate $(\sim 170 \mathrm{mmol}$ in the reactor) and then sealed. Electrode data were logged at intervals of $2 \mathrm{~s}$ for the first $4 \mathrm{~h}, 5 \mathrm{~min}$ for the next $20 \mathrm{~h}, 10$ min for the following $24 \mathrm{~h}, 30 \mathrm{~min}$ for the next 7 days, and $1 \mathrm{~h}$ for the remainder of the incubation (42 days total). Water was removed from the reactor via a syringe port while 
depressing the large piston to impede air from entering the reactor. ORP readings were converted to $E_{\mathrm{h}}$ values by adding $200 \mathrm{mV}$ to the ORP value (the potential difference between $\mathrm{Ag} / \mathrm{AgCl}$ and hydrogen electrodes).

\section{Microcosm Incubations}

Microcosm incubations were conducted in $60 \mathrm{~mL}$ clear glass bottles containing $\sim 15 \mathrm{~g}$ of wet sediment, $40 \mathrm{~mL}$ of artificial groundwater adjusted initially to $20 \mathrm{mM}$ in sodium acetate, and $5-10 \mathrm{~mL}$ of laboratory air and were sealed with gastight blue butyl rubber septa for up to 79 days. At each sampling event, two to four microcosm bottles were sacrificed for water and sediment analyses providing a total of 49 microcosm bottles. Water was removed from each bottle by piercing the septum with a nitrogen-filled syringe, injecting the nitrogen, then removing an equal volume of water with the same syringe.

\section{Geochemical Modeling}

Geochemist's Workbench software (Rockware Inc., Golden, CO) was used to examine mineral saturation states and to construct $E_{\mathrm{h}}-\mathrm{pH}$ diagrams. All calculations were conducted with the Lawrence Livermore National Laboratories combined database with published alterations $(16,36)$ updated for arsenic speciation $(24,26)$ (Supporting Information Table 2). To simplify calculations, aqueous iron-amino acid and iron-volatile organic acid complexes were suppressed; some formation of these complexes may be expected. Thioarsenites, specifically AsS $(\mathrm{OH})(\mathrm{SH})^{-}$and $\mathrm{As}_{3} \mathrm{~S}_{4}(\mathrm{SH})^{2-}$, from Nordstrom and Archer (24) were also suppressed; these data were assumed to have been superseded by thioarsenite data from Wilkin et al. (26). When the Nordstrom and Archer thioarsenites were not suppressed, they appeared in much the same $E_{\mathrm{h}}-\mathrm{pH}$ region as the Wilkin thioarsenites; however, consistency between these two data sets is beyond the scope of this research.

\section{Results and Discussion}

Iron oxidation states examined with ferrozine (35) indicated that $100 \%$ of the Fe within the uncertainty of the measurements $( \pm 15 \%)$ was $\mathrm{Fe}(\mathrm{II})$; these data are therefore not reported separately.

\section{Reactor and Microcosms}

Aqueous data from the reactor are shown in Figure 1. Temperature, electrical conductivity, turbidity, dissolved oxygen, ORP, and $\mathrm{pH}$ data were logged by the Horiba U-22 throughout the course of the reactor experiment (Figure 1A). DO data are not reported because DO remained at zero after the first $6 \mathrm{~h}$. Spikes in ORP were observed, which corresponded to observation of bubbles on the probe; these may have been air that had leaked into the reactor or $\mathrm{CO}_{2}$ and other gases that had formed within the reactor. Once observed, the bubbles were dislodged by tapping and tilting the vessel and by removal with a syringe via a syringe port. The one interval of significant $\mathrm{pH}$ decrease corresponded to a period of somewhat higher ORP (days $\sim 35-38$ ) when a relatively large bubble accumulated in the reactor over a weekend. The concentrations of dissolved aqueous species are shown in Figure 1B,C,D. Maxima for As, Fe, and Mn concentrations corresponded to the time of maximum electrical conductivity and occurred between 8 and 14 days; maximum concentrations were 1.9, 30, and $3 \mu \mathrm{M}$, respectively. Arsenic concentrations increased slightly from 28 to 41 days.

Two to four microcosms were sacrificed at each time point, standard deviations between replicates are shown in Figure 2, and analytical errors were negligible in comparison to variations between replicate samples. The IC samples taken at 0 days were lost, and therefore, acetate and sulfate concentrations at the start of the incubations were assumed to be 20 and $4.1 \mathrm{mM}$, respectively, the highest values measured in the microcosms; these 
values were slightly higher than the concentrations in the artificial groundwater, most likely due to equilibration with solids. Values measured in the reactor (Figure 1C) were yet higher, also likely due to equilibration with solids, and this may imply that initial acetate and sulfate values in the microcosms may have been higher than 20 and $4.1 \mathrm{mM}$, respectively. Fe and Mn concentrations showed maxima of $111 \mu \mathrm{M}$ at day 8 and $6.0 \mu \mathrm{M}$ at day 11 , respectively; concentrations then decreased rapidly and remained very low thereafter (Figure 2C). There was a maximum in [As] at 8 days $(2.05 \mu \mathrm{M})$ with a subsequent large decrease to $0.46 \mu \mathrm{M}$ by 13 days, followed by a second maximum of $1.6 \mu \mathrm{M}$ at 28 days and then continuous low values of $\sim 0.34 \mu \mathrm{M}$ for the remainder of the incubation until 79 days (Figure 2D).

The overall trend in both reactor and microcosm incubation experiments was toward progressively more reducing conditions with time as indicated by the ORP data and concentrations of aqueous species. Acetate and sulfate concentrations decreased and sulfide concentrations increased with time. As a result of increasingly reducing conditions, the incubations were expected to be characterized by initially increasing and subsequently decreasing $[\mathrm{Fe}],[\mathrm{Mn}]$, and [As]. Observations as a function of time from the reactor (Figure 1) and the first stages of the microcosm experiments (Figure 2) generally conformed to these expectations. However, [As] in the later stages of the microcosms behaved quite differently.

$\mathrm{Fe}$ and Mn data as a function of time are consistent with reducing conditions progressively increasing in strength in both reactor and microcosms; the initial increase in $[\mathrm{Fe}]$ and $[\mathrm{Mn}]$ can be accounted for by dissolution of Fe and Mn (hydr)-oxides and the subsequent decrease in $[\mathrm{Fe}]$ and $[\mathrm{Mn}]$ by formation of carbonate minerals, formation of sulfide minerals, and/or decreased solubility of $\mathrm{Fe}$ (hydr)oxides under higher $\mathrm{pH}$ conditions $(37,38)$. Note that field conditions beneath the landfill are most analogous to the time point with maximum $\mathrm{Fe}, \mathrm{As}$, and Mn concentrations.

\section{Mass Balances and Solid-Phase Transformations}

Calculations using the React module of Geochemist's Workbench indicate that mineral formation in the microcosms fell into three periods. From 0 to 6 days, no minerals were supersaturated, and from 8 to 11 days, iron oxides and carbonates were supersaturated. From day 13 to the end of the incubations, carbonate minerals (such as dolomite) were intermittently supersaturated or near saturation, depending on the alkalinity value measured. From day 13 to the end of the incubations, iron and arsenic sulfides were supersaturated.

Mass balances from these time periods and equivalent time periods in the reactor were calculated and are shown in the Supporting Information (Tables 3 and 4), although it was not possible to fully balance the elements due to the lack of quantitative solid-phase data. Additionally, a rough electron balance for the microcosm experiments was calculated. The oxidation of acetate to $\mathrm{CO}_{2}$ (or carbonate) released about $8 \mathrm{mmol}$ of electrons to solution (per microcosm bottle). A total of $\sim 1.6 \mathrm{mmol}$ of these electrons was consumed by sulfate reduction, and another $\sim 0.4 \mathrm{mmol}$ was consumed by reduction of $\mathrm{O}_{2}$ in the headspace. This leaves $6 \mathrm{mmol}$ of electrons that we assume were partitioned between methane formation and reduction of iron. Qualitative data indicate that high methane concentrations formed, but due to problems with the analysis method, methane was not quantifiable.

\section{Arsenic Speciation}

The temporal trends of dissolved As and $\mathrm{Fe}$ are consistent with thermodynamic expectations (Figure 3), although the temporal trend of As concentrations in the microcosm incubations (Figure 2D) was more complex than the iron trend. To explore the implications of these temporal trends, $\mathrm{Fe}$ and As speciation as functions of $E_{\mathrm{h}}$ and $\mathrm{pH}$ were determined (Figure 3). The discrete time points selected were chosen to represent extreme conditions with respect 
to As behavior in the microcosms, such as local maxima and minima of [As]. These time points were located in the $E_{\mathrm{h}}-\mathrm{pH}$ space by two methods: (i) $E_{\mathrm{h}}$ was calculated with Geochemist's Workbench from the $\mathrm{HS}^{-} / \mathrm{SO}_{4}{ }^{2-}$ redox couple, except for those samples where $\mathrm{CH}_{4}$ was detected; for those samples, $E_{\mathrm{h}}$ was calculated from the $\mathrm{CH}_{4} / \mathrm{CO}_{2}$ redox couple. It was found that the $E_{\mathrm{h}}$ value was relatively insensitive to the concentration of methane but was quite sensitive to its presence, so the lack of quantitative methane data did not present a problem. (ii) $E_{\mathrm{h}}$ and $\mathrm{pH}$ were estimated in the microcosms by comparison between the microcosms and the reactor, for which $E_{\mathrm{h}}$ and $\mathrm{pH}$ values were available; these values were used as a consistency check against the Geochemist's Workbench values and were found to be in good agreement.

One may follow the experiment through time in Figure 3 and note that at each selected time point, the $E_{\mathrm{h}}$ and $\mathrm{pH}$ values imply arsenic and iron speciation consistent with the concentrations of these species seen in solution. However, it is important to note that disequilibrium processes (39) may have dominated. Relevant field experiments (40) indicate that on a time scale of 2-3 months, sulfate reduction can remove a high proportion of dissolved metals, regardless of transient species formed.

\section{Aqueous Thioarsenite Chemistry}

The most striking feature of the microcosm incubations was the second peak in the arsenic concentration; no analogous observations have been reported, of which we are aware, in previous laboratory experiments promoting growth of sulfate-reducing bacteria using materials from acid mine drainage sites $(20,21)$. We attribute this peak in our experiments to the formation of aqueous thioarsenite species; such species have previously been studied in the laboratory $(25,26,41)$ and have recently been observed (42) in the field. However, as previously noted, this second arsenic peak may be due to a metastable species or transient process not adequately modeled with a thermodynamic model such as Geochemists' Workbench.

Equilibria between arsenite and thioarsenites were examined for day 28 in the microcosms (see Supporting Information Table 2), which was the time of maximum sulfide concentration and the second arsenic peak. When equilibria of these thioarsenite species were considered together, very little $\mathrm{As}(\mathrm{OH})_{3}$ was calculated to be present in the microcosms at day 28, and the dominant As species in solution was calculated to be $\mathrm{AsS}_{3}{ }^{3-}$. Unlike the microcosms, the reactor incubation did not have a second As peak, although [As] had begun to rise slightly when the experiment was terminated. It is possible that a second arsenic peak would have occurred later in the reactor had the incubation continued.

\section{Comparison to Field Data}

Conditions in the incubations were similar, but not identical, to several field parameters for the site in southern Maine (3). The initial $\mathrm{pH}$ of artificial groundwater used for the incubation experiments was higher than that observed in the field, despite similar concentrations of major ions (Supporting Information Table 1). At $\mathrm{pH}$ values more characteristic of the field data, aqueous thioarsenites would still be expected to form (Figure 3 ). Although the groundwater $\mathrm{pH}$ was lower in the field than in artificial groundwater used in incubations, it was still much less acidic than the $\mathrm{pH}$ associated with previous investigations of sulfate reduction to induce arsenic immobilization at acid mine sites (20, 21).

Maximum arsenic concentrations in all incubations were significantly lower than those observed in the field; the reactor and microcosms had maximum values of 1.45 and $2.05 \mu \mathrm{M}$ $\mathrm{L}^{-1}$ As, respectively, as compared to $\sim 4 \mu \mathrm{M}$ in the field. Iron concentrations were also lower 
in the laboratory incubations with at most $\sim 110 \mu \mathrm{M}$ in the microcosms versus $\sim 660 \mu \mathrm{M}$ in the field. These differences could reflect lower solid-water ratios in the incubation experiments $(\sim 1 / 3)$ as compared to the aquifer $(\sim 4 / 1)$. Another plausible explanation for these systematic differences is that mobilization of As via reductive dissolution of $\mathrm{Fe}$ minerals, a plausible process to cause elevated [As] in groundwater, is known to be rather slow $(43,44)$ and could be incomplete in the microcosms when the As immobilizing processes such as sulfate reduction began.

Sulfide was occasionally detected in field samples; in these samples, data are consistent with some in situ formation of thioarsenites, and these may represent a fraction of aqueous arsenic found at the site. Additionally, Geochemist's Workbench calculations indicate that when sulfide was present in the field, iron and arsenic sulfides are supersaturated. This raises the question as to why As immobilization, similar to that observed in this laboratory study, is not seen in the field. It is possible that some arsenic immobilization is occurring at this site but that immobilization processes are too slow to allow appreciable decreases in dissolved arsenic concentrations; some authigenic sulfide minerals have been observed and may be high in As (10). Additionally, the majority of field samples does not show dissolved sulfide. This may imply that all sulfide formed is immediately consumed by available iron. Alternately, preliminary incubation experiments (data not shown) indicate that the system is carbon limited and that $\mathrm{SO}_{4}$ reduction may occur too slowly to release appreciable sulfide to the system without a perturbation such as acetate addition. Field data are not sufficient to explore this question further at this time.

\section{Effectiveness of Arsenic Sequestration}

For enhanced sulfate reduction to be an effective groundwater remediation strategy for arsenic, this approach should remove a large proportion of arsenic from solution. In the reactor, $0.6 \mu \mathrm{M}$ As was removed from solution (representing a $\sim 50 \%$ decrease from maximum [As]), and in the microcosms, $1.7 \mu \mathrm{M}$ As (representing a $~ 85 \%$ decrease from maximum [As]) was removed from solution. These percentages were calculated by subtracting the final concentration from the maximum concentration because the maximum As and Fe concentrations were most analogous geochemically to the field conditions.

Arsenic concentrations in the field were generally higher than achieved in these incubation experiments. The higher concentrations of As to be removed would probably not present a problem since a larger fraction of arsenic was removed from solution in the microcosms than in the reactor: the maximum [As] was lower, and the final [As] was higher in the reactor. This indicates that the proportion of As removed from the microcosms was not limited by the arsenic removal capacity of the system, but rather, the minimum [As] achieved may have been controlled by equilibria between authigenic mineral phases and aqueous phase. The somewhat more strongly reducing conditions probably achieved in the microcosms may have permitted a sediment-water equilibrium more favorable to lower [As].

The second arsenic peak may initially raise concerns about induced sulfate reduction as a remediation method, but these concerns may not be justified. First, if this peak is interpreted to be due to aqueous thioarsenite formation, the formation of these species has been shown to be suppressed by higher aqueous iron concentrations $(16,28)$. Higher [Fe] could suppress aqueous thioarsenite formation but also permit the formation of solid arsenic sulfides, promote the formation of iron sulfides to which arsenic oxyanions could sorb $(12,13)$, or inhibit formation of sediment As sinks essential for sulfate reduction to act as an As remediation strategy. Second, this peak may have been due to the formation of other species, the identities of which are not known; what is known is that the species formed appear to be transient and relatively short-lived. Finally, assessment of the viability of induced sulfate 
reduction as a remediation method should be made from a combination of this laboratory experiment, other laboratory experiments, and in situ trials wherever possible.

\section{Supplementary Material}

Refer to Web version on PubMed Central for supplementary material.

\section{Acknowledgments}

The research outlined here was supported through NIEHS Grants P42 ES10349 and P30 ES09089. Materials for the incubation experiments derived from the Winthrop Landfill site were made available by the United Technologies Corporation, as were the groundwater chemical monitoring data from that site. This is LDEO Publication 7052.

\section{Literature Cited}

1. US EPA Arsenic Treatment Technologies for Soil, Waste, and Water. U.S. EPA; Washington, DC: 2002. http://www.clu-in.org/download/remed/542r02004/arsenic_report.pdf

2. US EPA Basic Query Form, National Priorities List Superfund. U.S. EPA; Washington, DC: 2005. http://www.epa.gov/superfund/sites/query/basic.htm

3. Keimowitz AR, Simpson HJ, Stute M, Datta S, Chillrud SN, Ross J, Tsang M. Naturally-occurring arsenic: Mobilization at a landfill in Maine and implications for remediation. Appl Geochem. 2005; 20:1985-2002.

4. Mayo MJ, Hon R, Brandon WC, Ford R. Arsenic in groundwater at landfill sites in north central Massachusetts. Proceedings of the American Chemical Society. 2003; 226:594-594.

5. DeLemos JL, Bostick BC, Renshaw CE, Stürup S, Feng X. Landfill-stimulated iron reduction and arsenic release at the Coakley Superfund Site (NH). Environ Sci Technol. 2006; 40:67-73. [PubMed: 16433334]

6. Voudrias EA. Pump-and-treat remediation of groundwater contaminated with hazardous waste: Can it really be achieved? Global NEST: Intl Network. 2001; 3:1-10.

7. Keimowitz, AR.; Simpson, HJ.; Chillrud, SN.; Stute, M.; Tsang, M.; Datta, S.; Ross, J. Oxidation of groundwater arsenic and iron. In: O’Day, PA.; Vlassopoulos, D.; Meng, D.; Benning, LG., editors. Advances in Arsenic Research: Integration of Experimental and Observational Studies and Implications for Mitigation; ACS Symposium Series; Washington, DC: American Chemical Society; 2005. p. 915

8. Dixit S, Hering JG. Comparison of $\operatorname{arsenic}(\mathrm{V})$ and arsenic(III) sorption onto iron oxide minerals: Implications for arsenic mobility. Environ Sci Technol. 2003; 37:4182-4189. [PubMed: 14524451]

9. Pierce ML, Moore CB. Adsorption of arsenite and arsenate on amorphous iron hydroxide. Water Res. 1982; 16:1247-1253.

10. Kober R, Welter E, Ebert M, Dahmke A. Removal of arsenic from groundwater by zerovalent iron and the role of sulfide. Environ Sci Technol. 2005; 39:8038-8044. [PubMed: 16295872]

11. Puls RW, Paul CJ, Powell RM. The application of in situ permeable reactive (zero-valent iron) barrier technology for the remediation of chromate-contaminated groundwater: A field test. Appl Geochem. 1999; 14:989-1000.

12. Bostick BC, Fendorf S. Arsenite sorption on troilite $(\mathrm{FeS})$ and pyrite $\left(\mathrm{FeS}_{2}\right)$. Geochim Cosmochim Acta. 2003; 67:909-921.

13. Huerta-Diaz MA, Tessier A, Carignan R. Geochemistry of trace metals associated with reduced sulfur in freshwater sediments. Appl Geochem. 1998; 13:213-233.

14. Wolthers M, Charlet L, Van der Weijden CH, Van der Linde PR, Rickard D. Arsenic mobility in the ambient sulfidic environment: Sorption of $\operatorname{arsenic}(\mathrm{V})$ and $\operatorname{arsenic}(\mathrm{III})$ onto disordered mackinawite. Geochim Cosmochim Acta. 2005; 69:3483-3492.

15. Bostick BC, Chen C, Fendorf S. Arsenite retention mechanisms within estuarine sediments of Pescadero, CA. Environ Sci Technol. 2004; 38:3299-3304. [PubMed: 15260327] 
16. O'Day PA, Vlassopoulos D, Root R, Rivera N. The influence of sulfur and iron on dissolved arsenic concentrations in the shallow subsurface under changing redox conditions. Proc Natl Acad Sci US A. 2004; 101:13703-13708.

17. Kirk MF, Holm TR, Park J, Jin QS, Sanford RA, Fouke BW, Bethke CM. Bacterial sulfate reduction limits natural arsenic contamination in groundwater. Geology. 2004; 32:953-956.

18. Morse JW, Millero FJ, Cornwell JC, Rickard D. The chemistry of the hydrogen sulfide and iron sulfide systems in natural waters. Earth Sci Rev. 1987; 24:1-42.

19. Benner SG, Blowes DW, Ptacek CJ, Mayer KU. Rates of sulfate reduction and metal sulfide precipitation in a permeable reactive barrier. Appl Geochem. 2002; 17:301-320.

20. Rittle KA, Drever JI, Colberg PJS. Precipitation of arsenic during bacterial sulfate reduction. Geomicrobiol J. 1995; 13:1-11.

21. Jong T, Parry DL. Removal of sulfate and heavy metals by sulfate reducing bacteria in short-term bench scale upflow anaerobic packed bed reactor runs. Water Res. 2003; 37:3379-3389. [PubMed: 12834731]

22. Jong T, Parry DL. Adsorption of Pb(II), Cu(II), Cd(II), Zn(II), Ni(II), Fe(II), and As(V) on bacterially produced metal sulfides. J Colloid Interface Sci. 2004; 275:61-71. [PubMed: 15158381]

23. Jong T, Parry DL. Heavy metal speciation in solid-phase materials from a bacterial sulfate reducing bioreactor using sequential extraction procedure combined with acid volatile sulfide analysis. J Environ Monit. 2004; 6:278-285. [PubMed: 15054535]

24. Nordstrom, DK.; Archer, DG. Arsenic thermodynamic data and environmental geochemistry. In: Welch, AH.; Stollenwerk, KG., editors. Arsenic in Ground Water: Geochemistry and Occurrence. Kluwer Academic Publishers; Dordrecht, The Netherlands: 2003.

25. Eary LE. The solubility of amorphous As $2 \mathrm{~S} 3$ from 25 to $90{ }^{\circ} \mathrm{C}$. Geochim Cosmochim Acta. 1992; 56:2267-2280.

26. Wilkin RT, Wallschlager D, Ford RG. Speciation of arsenic in sulfidic waters. Geochem Trans. 2003; 4:1-7.

27. Lee MK, Saunders JA. Effects of $\mathrm{pH}$ on metal precipitation and sorption: Field bioremediation and geochemical modeling approaches. Vadose Zone J. 2003; 2:177-185.

28. Lee, M-K.; Saunders, JA.; Harrington, J.; Lutes, C.; Wilkin, RT. Remediation of Recalcitrant Contaminants. Battelle Press; Columbus, OH: 2005. Strategy for in situ bioremediation of arsenic in groundwater: Field and modeling studies.

29. Lackovic JA, Nikolaidis NP, Dobbs GM. Redox-sensitive mobility of arsenic in proximity to a municipal landfill. Hazard Indust Wastes. 1999; 31:451-459.

30. US EPA NPL Site Narrative for Winthrop Landfill, NPL, Superfund. U.S. EPA; Washington, DC: 1983. http://www.epa.gov/superfund/sites/npl/nar36.htm

31. Smedley PL, Kinniburgh DG. A review of the source, behavior, and distribution of arsenic in natural waters. Appl Geochem. 2002; 17:517-568.

32. Ayotte JD, Montgomery DL, Flanagan SM, Robinson KW. Arsenic in groundwater in eastern New England: Occurrence, controls, and human health implications. Environ Sci Technol. 2003; 37:2075-2083. [PubMed: 12785510]

33. Keimowitz AR, Zheng Y, Chillrud SN, Mailloux BJ, Jung HB, Stute M, Simpson HJ. Arsenic redistribution between sediments and water near a highly contaminated source. Environ Sci Technol. 2005; 39:8606-8613. [PubMed: 16329197]

34. Clesceri, LS.; Greenberg, AE.; Eaton, AD. Standard Methods for the Examination of Water and Wastewater. 20. American Public Health Association; Washington, DC: 1996.

35. Stookey LL. Ferrozine: A new spectrophotometric reagent for iron. Anal Chem. 1970; 42:779-781.

36. Delany, JM.; Lundeen, SR. The LLNL Thermochemical Database. Lawrence Livermore National Laboratory; Livermore, CA: 1990.

37. Masscheleyn PH, Delaune RD, Patrick WH. Effect of redox potential and $\mathrm{pH}$ on arsenic speciation and solubility in contaminated soil. Environ Sci Technol. 1991; 25:1414-1419.

38. Welch AH, Westjohn DB, Helsel DR, Wanty RB. Arsenic in ground water of the United States: Occurrence and geochemistry. Ground Water. 2000; 38:589-604. 
39. Rochette EA, Bostick BC, Li GC, Fendorf S. Kinetics of arsenate reduction by dissolved sulfide. Environ Sci Technol. 2000; 34:4714-4720.

40. Saunders JA, Lee MK, Wolf LW, Morton CM. Geochemical, microbiological, and geophysical assessments of anaerobic immobilization of heavy metals. Bioremed J. 2005; 9:33-48.

41. Helz GR, Tossell JA, Charnock JM, Pattrick RAD, Vaughan DJ, Garner CD. Oligomerization in As(III) sulfide solutions: Theoretical constraints and spectroscopic evidence. Geochim Cosmochim Acta. 1995; 59:4591-4604.

42. Hollibaugh JT, Carini S, Gurleyuk H, Jellison R, Joye SB, LeCleir G, Meile C, Vasquez L, Wallschlager D. Arsenic speciation in Mono Lake, CA: Response to seasonal stratification and anoxia. Geochim Cosmochim Acta. 2005; 69:1925-1937.

43. van Geen A, Rose J, Thoral S, Garnier JM, Zheng Y, Bottero JY. Decoupling of As and Fe release to Bangladesh groundwater under reducing conditions. Part II: Evidence from sediment incubations. Geochim Cosmochim Acta. 2004; 68:3475-3486.

44. Horneman A, van Geen A, Kent DV, Mathe PE, Zheng Y, Dhar RK, O'Connell S, Hoque MA, Aziz Z, Shamsudduha M. Decoupling of As and Fe release to Bangladesh groundwater under reducing conditions. Part I: Evidence from sediment profiles. Geochim Cosmochim Acta. 2004; 68:3459-3473. 

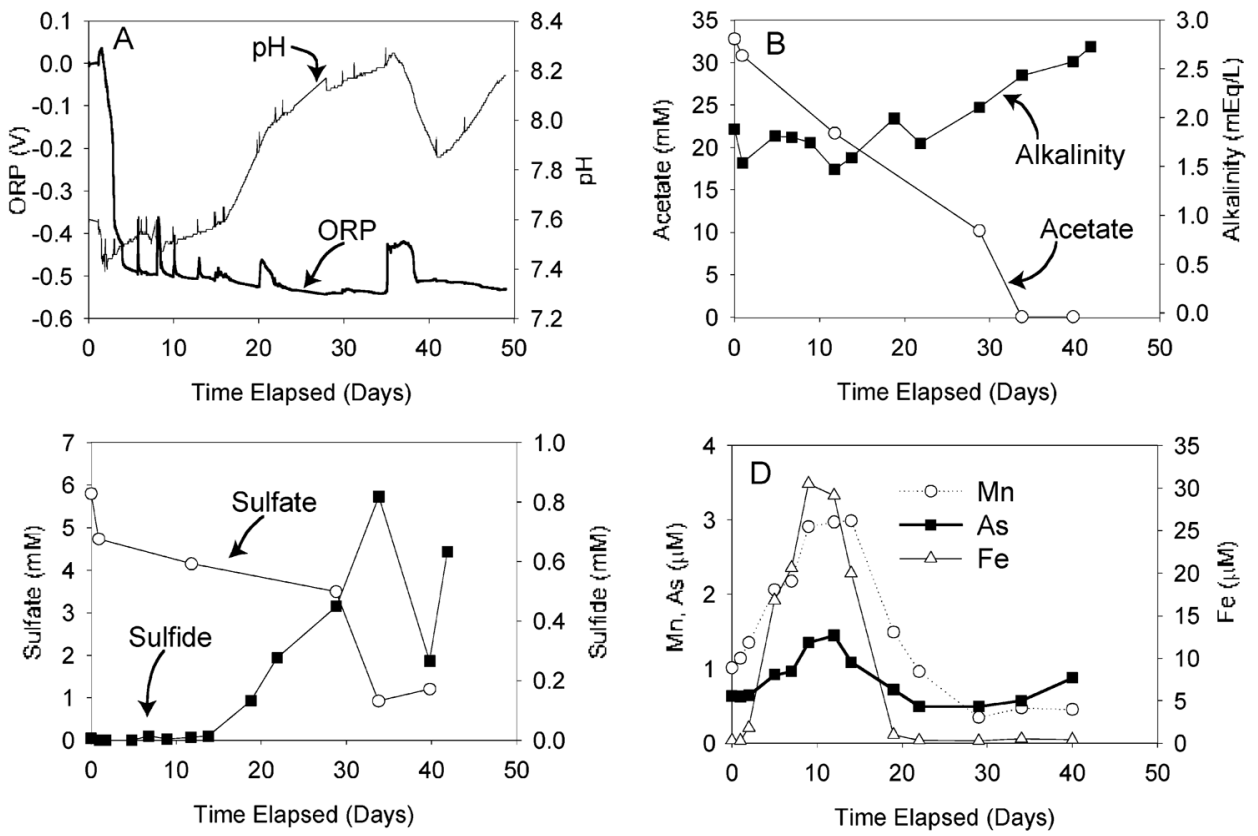

FIGURE 1.

Reactor incubation data. (A) ORP and pH data; (B) alkalinity and acetate; (C) sulfate and sulfide; and (D) As, Fe, and Mn. Initial nonzero values of As, Fe, and $\mathrm{Mn}$ are due to immediate equilibration with the sediments. 

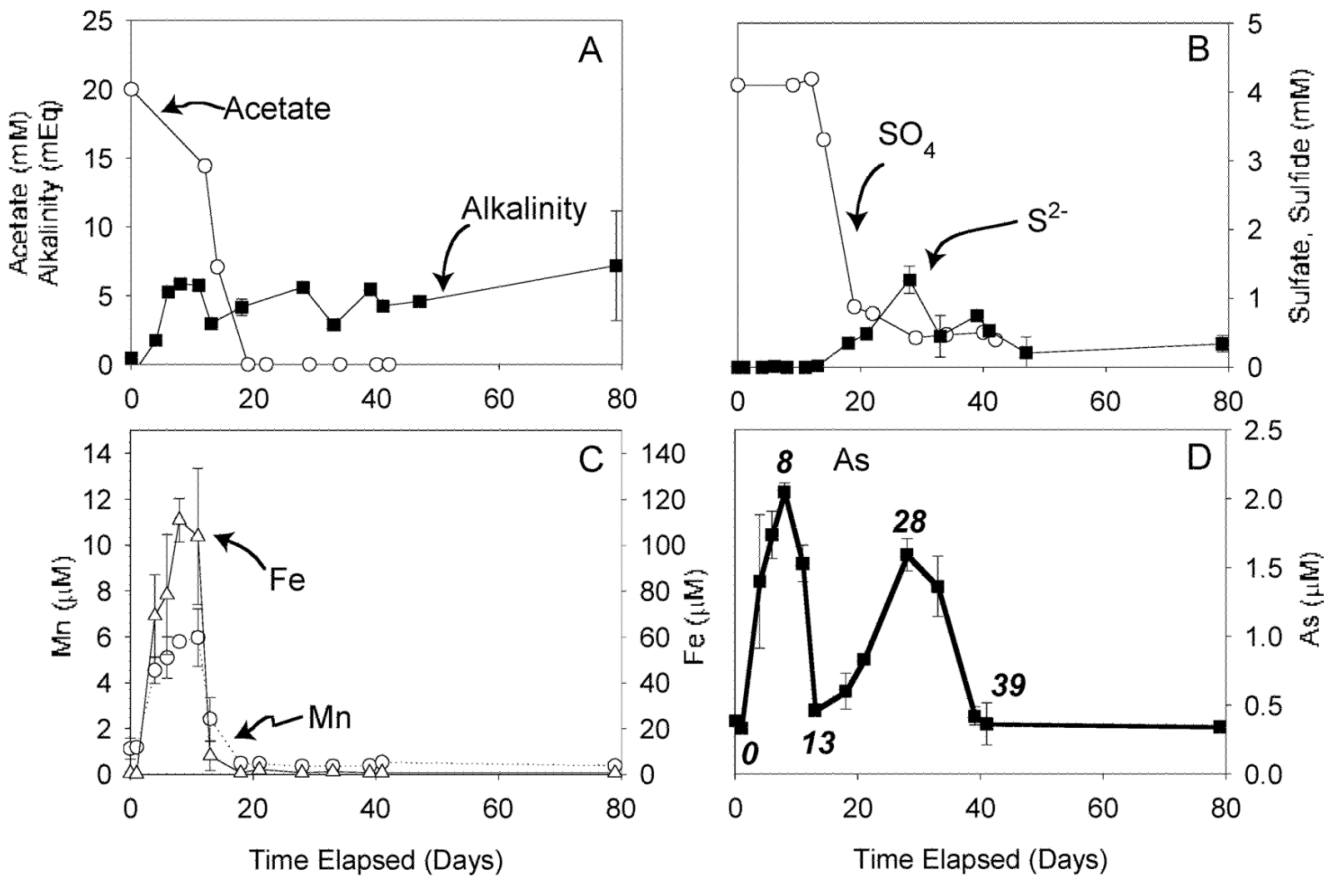

FIGURE 2.

Aqueous data from microcosm incubations. (A) Acetate and alkalinity; (B) sulfate by IC, sulfide by colorimetry, and total S by ICP-MS; (C) Fe and Mn, each with different axes; and (D) As. Note that the sulfide axis is $10 \times$ larger than in Figure 1 (reactor data). Time points shown in Figure 3 are also displayed in panel D. 


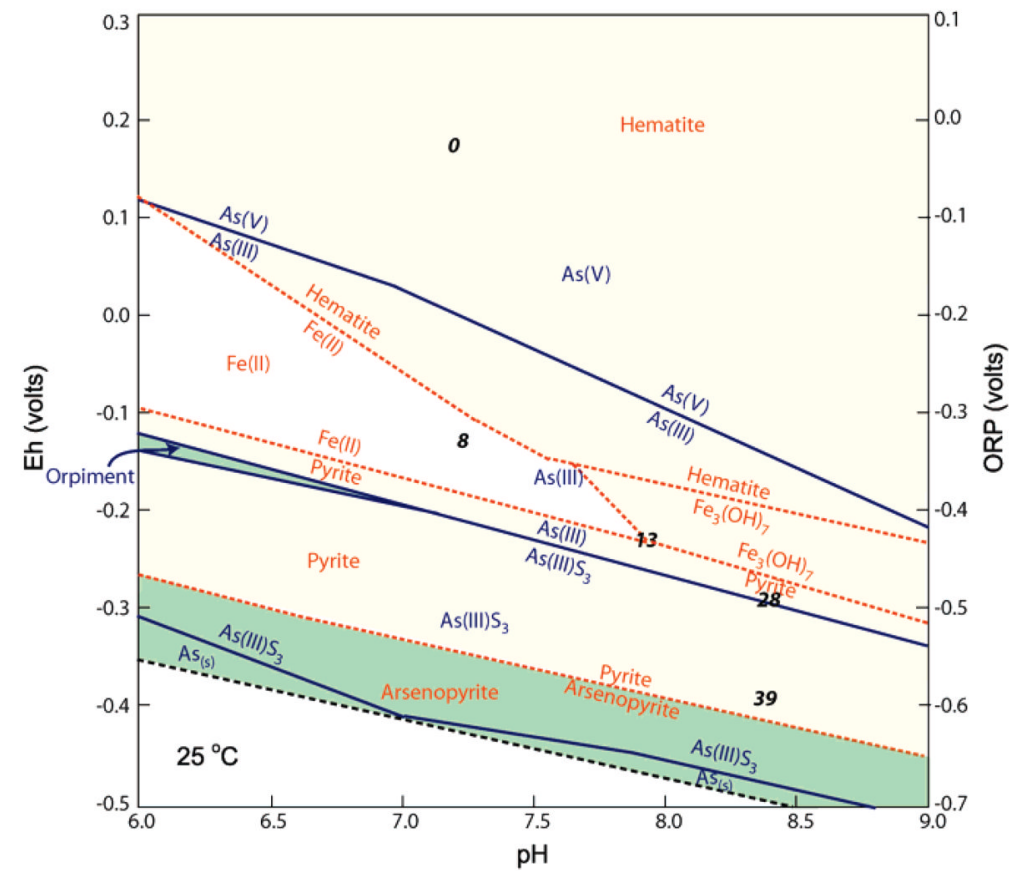

FIGURE 3.

$E_{\mathrm{h}}-\mathrm{pH}$ diagram derived from the Act2 module of Geochemist's Workbench software showing both As and Fe speciation; initial (i.e., $t=0$ ) aqueous geochemical data from microcosm incubations were used to generate this plot. Boundaries between As species are shown in solid blue lines, and those between Fe species are shown with dashed orange lines. Regions where the stable phases of neither iron nor arsenic are solid are shown with a white background, regions where the stable iron species is solid are shown with a yellow background, and regions where the stable species of both iron and arsenic are solid are shown with a green background. Boundaries between species that differ only with respect to protonation (e.g., $\mathrm{HAsO}_{4}{ }^{-}$and $\mathrm{H}_{2} \mathrm{AsO}_{4}{ }^{2-}$ ) are not included. Estimated $E_{\mathrm{h}}$ and $\mathrm{pH}$ values of days $0,8,13,28$, and 39 of the microcosm incubations are shown in black; were day 79 shown, it would not be distinguishable from day 39. Use of data from other microcosm sampling days and/or the $\mathrm{SO}_{4}$ concentration at day $0(4.1 \mathrm{mM})$ did not appreciably perturb the basic structure of Figure 3. 